\title{
Steering towards a Developmental Account of Infant Social Understanding
}

\author{
James Stack Charlie Lewis \\ Lancaster University, Lancaster, UK
}

The past few years have witnessed a renaissance in studies of very early social understanding. Having been largely eclipsed by the assumption made in the 'theory of mind' literature that social development is driven in the fourth year of life, this regeneration resulted from some fascinating empirical findings. Yet we contend that clear theoretical advances are needed to explain these fascinating data.

While much of this debate has been stimulated by research on infant perceptual preferences, social interactional skills, joint attention, and early language use, perhaps it is the findings of both Onishi and Baillargeon [2005] and Surian, Caldi and Sperber [2007] that are the most dramatic, appealing, and yet contentious in equal measure. They provide evidence to suggest that toddlers look longer at an event when an agent appears to act contrary to what would be expected from her previous actions - e.g., reaching to a yellow box after she has placed an object in the green one and the object has moved in her absence. Such findings have led to two explanations based upon well-worn and, we contend, ultimately doomed lines of argument - the Scylla of nativism and the Charybdis of associationism.

The parallels between this nonverbal violation-of-expectation task and the unexpected transfer false belief test [Wimmer \& Perner, 1983] have led Onishi and Baillargeon [2005] to suggest that '15-month-old infants already possess (at least in a rudimentary and implicit form) a representational theory of mind' (p. 257), and Surian, Caldi and Sperber [2007] to contend 'that infants possess an incipient metarepresentational ability that permits them to attribute beliefs to agents' (p. 580). If correct, these 'rich' nativist interpretations suggest a need for a dramatic reappraisal of our understanding of the developmental progression toward belief state reasoning in early childhood. Leslie [2005] has built on these findings to argue that a specialised neurocognitive system (ToMM or theory of mind module) [Leslie, 1987] may now account for pretend, desire, and belief representations within the first two years of life: 'Suddenly, the idea of early ToMM is not so crazy after all' (p. 460).

Yet there are several reasons why we should be cautious about this nativist claim. It hinges on how data from paradigms like 'infant false belief' are interpreted. The debates go back a long while. For example, 'rich' interpretations of Woodward's [1998] fascinating reaching studies assumed that infants show an awareness of

\begin{tabular}{ll}
\hline KARGER & ( ) 2008 S. Karger AG, Basel \\
Fax +41 61 306 12 34 & 0018-716X/08/0514-0229\$24.50/0 \\
$\begin{array}{l}\text { E-Mail karger@karger.ch } \\
\text { www.karger.com }\end{array}$ & $\begin{array}{l}\text { Accessible online at: } \\
\text { www.karger.com/hde }\end{array}$
\end{tabular}

Charlie Lewis

Psychology Department, Fylde Building Lancaster University, Lancaster LA1 4 YF (UK) Tel. +44 1524593 822, Fax +44 1524593744 E-Mail c.lewis@lancaster.ac.uk 
agents' goal-directed actions within their first year. Yet 'lean' accounts suggest that these findings demonstrate no more than infants' awareness of object-directed actions [e.g., Behne et al., 2005] or 'non-mentalistic' processes [e.g., Gergely \& Csibra, 2003]. To our minds, the findings on 'infant false belief' have to be understood in terms of the evidence which demonstrates an infant's understanding of agents' actions and perceptions within non-shared environments without invoking higher metarepresentational belief state explanations [e.g., Luo \& Baillargeon, 2007; Moll \& Tomasello, 2004, 2007; O’Neill, 1996; Poulin-Dubois et al., 2007; Sodian, Thoermer, \& Metz, 2007; Sodian \& Thoermer, 2008; Tomasello \& Haberl, 2003].

Let us explore one example. Onishi and Baillargeon's [2005] 'false belief' condition is characterised by the infant having full perceptual access to changes within a non-shared environment. Thus, such 'new' information (e.g., unexpected transfer) is not afforded to the agent. This is analogous to the three toys studies provided by Tomasello and colleagues [Moll, Carpenter, \& Tomasello, 2007; Moll \& Tomasello, 2007; Tomasello \& Haberl, 2003]. In these studies, infants engaged with an experimenter, a second person (assistant or mother), and two toys. The second person then left the room and a third toy was introduced. Upon returning to the scene this person made excited utterances in the general direction of all three toys. Consistent with Onishi and Baillargeon [2005], these findings clearly demonstrated that infants early within their second year have the same capacity to monitor an agent's level of perceptual awareness, and that they manifest an ability to default to this third-person perspective (e.g., they know that the third toy is 'new' for this person). Moll et al. provided evidence for infants' ability to distinguish between their own and others' viewpoint, and also what agents have and have not experienced. But why does their work lead us away from a simple nativist perspective?

Consider the key findings from Moll and Tomasello [2007]. They assessed three conceptually distinct forms of infant social experience with the 'new' toy paradigm, involving (1) joint engagement between infant and experimenter, (2) the infant watching as the adult individually engages, and (3) the infant individually engaging with objects while the adult passively observes. Two key points deserve mention. First, neither 14- nor 18-month-olds benefited from an adult merely onlooking as the infant and a second person interacted with the toys, whereas both age groups benefited from a prior episode of joint engagement. Second, 18- but not 14-month-olds performed at above chance levels when their prior experience merely involved passively watching the adult interacting with toys. Rather than revealing inborn competences, such data suggest a developmental story in which (1) 14-month-olds are particularly sensitive to rich triadic forms of social engagement, and (2) at some point between 14 and 18 months a competence develops which allows social understanding simply through observation of others' actions.

The nativist metarepresentational account should also receive critical attention because of its reliance on two methods, preferential looking and violation of expectations. It provides a view of infant social understanding that, though being based on no more than a look, would in Fischer and Biddell's [1991] terms appear 'excessively adultocentric' [see also Haith, 1998]. For example, on the basis of preferential looking Onishi and Baillargeon [2005] asserted that 'infants realize that others act on the basis of their beliefs and that these beliefs are representations [italics added] that may or may not mirror reality' (p. 257). Haith, however, pointed out that 'the suitability of cognitive constructs for the infant at any particular age may be similar 
to the embryologist's dilemma when asked to decide when a cell cluster is a brain, or an eye, or a heart' (p. 177). He built on this point to argue that while the problems of appropriate identification and labelling are clearly defined for the embryologist, infancy researchers 'don't even have the luxury of knowing with certainty what the primordial structures are for the construct and competencies we entertain' (p. 177). As Aslin [2007] pointed out: 'In the absence of a more direct measure of neural information processing, a look is merely a correlate of the underlying neural activity that mediates detection, discrimination, or categorization of visual stimuli in a specific behavioural paradigm' (p. 50).

The Scylla of nativism is the appeal of a neatly packaged set of a priori skills in social understanding. This lures us away from a focus on how such abilities actually emerge [Haith, 1998; Sirois \& Jackson, 2007] and possibly into the jaws of an oversimple, yet at the same time overegged, account of development. The current alternative [Perner \& Ruffman, 2005; Ruffman \& Perner, 2005] is that Onishi and Baillargeon's [2005] test trial outcomes can be equally well explained in perceptual terms based on behavioural rules (e.g., agent looks for $\mathrm{x}$ where she last saw $\mathrm{x}$ ) and three-way associations (agents' perception of objects at locations) resulting from exposure during familiarisation trials.

These latter three-way associations are thought to result in a rapid increase in neuronal firing at this period and determine lower processing demands, and subsequently lower looking times for consistent actions during test trials. The Charybdis whirlpool of three-way associationism appears equally dangerous as this line of reasoning has no real empirical or developmental support. The evidence referred to is based on animal data [Wan, Aggleton, \& Brown, 1999] which demonstrate increased neuronal activation in the rat's postrhinal and hippocampal regions following new arrangements of three familiar stimuli. Csibra and Southgate [2005] dismissed this tenuous comparative argument for being based on research which 'hypothesized rather than demonstrated the forming of associations in the prefrontal cortex between two rather than three stimulus features' (p. 4, emphasis in original).

Perner and Ruffman [2005] conceded that the associationist interpretation is open to empirical assessment. Their position is that the infant's exposure to an agent's perceptual awareness of objects at locations during familiarisation trials is key to the infant's preferential looking, not the agent's actions at locations (intentional or non-intentional) during test trials. Yet perhaps this statement is overly ambitious considering that previous findings have demonstrated infants' proclivity to imbue their worlds within an intentional, purposeful, and goal-directed manner [e.g., Behne et al., 2005; Carpenter, Nagell, \& Tomasello, 1998; Woodward, 1999]. For example, Woodward's classic study demonstrated a significant reduction in infant looking times depending on whether the agent re-engaged with a toy in a purposeful goal-directed (grasp) manner, contrasting with no difference between old and new goal actions when performed in a non-purposeful (back-of-the-hand) manner. Perner and Ruffman's [2005] associationism argument may actually not fully explain the richness of data from Woodward and related studies, which show that some circumstances facilitate whether the infant makes associations between agents and objects.

The behavioural rules account outlined by Perner and Ruffman [2005], described above, may provide a more plausible account than that offered by the threeway association critique and Onishi and Baillargeon's [2005] metarepresentational

Steering towards a Developmental Account of 
interpretation, in that it attempts closely to describe infants' knowledge of agents' levels of perceptual awareness within non-shared environments [e.g., O’Neill, 1996; Tomasello \& Haberl, 2003]. But in other respects it appears to fail on a number of key issues, particularly how these rules emerge to become part of the child's repertoire. Perner and Ruffman even concede that the nativist position must hold in part: 'Infants may have noticed (or are innately predisposed to assume) that people look for an object where they last saw it and not necessarily where the object actually is' [Perner \& Ruffman, 2005, p. 215]. Like Onishi and Baillargeon [2005], Perner and Ruffman appear guilty of providing 'top-down' experimenter-based inferences [e.g., Haith, 1998; Sirois \& Jackson, 2007]. This account has not received universal acclaim. For example, in their critique of Perner and Ruffman's behavioural rules account, Surian, Caldi and Sperber [2007, p. 585] stated: 'This appears to be the case of jumping into the river of ad hoc nativist stories in order to avoid being doused by the more principled nativist hypothesis that the mind-reading humans demonstrate at 4 years is based on a strong biological predisposition that is already manifest in infants' rudimentary ability to attribute mental content to agents.'

We sense that recent studies are making a break from the associationist tradition. For example, the recent paper by Sodian and Thoermer [2008] is an attempt to unpack the processes involved in the development of social understanding. Their findings here suggest that (1) 16-month-old infants' action predictions (looking times) are based on behavioural and situational cues, and that (2) behavioural cues facilitate 18-month-olds' action predictions when interpreting another person's level of perceptual awareness. Whilst useful in providing a gradualist picture of the conditions for knowing within the second year, what appears problematic here is the 'top-down' emphasis upon the infant as a 'rule user' without any account of how social processes facilitate such learning [e.g., Moll, Carpenter, \& Tomasello, 2007; Moll \& Tomasello, 2007].

In empirical terms, a safer route towards understanding infant social competence would be to use a diversity of methods, including those employing looking times, that assess both the macro- and microstructural levels of infants' real time actions and gestures. Aslin [2007] has argued that analysis of global looking times (macrostructure) includes coding a mixture of active information processing and inactive blank stares. He suggested that there is a need for a more extensive use of devices like automated eye trackers [e.g., Southgate, Senju, \& Csibra, 2007] to go beyond this very general measure. More importantly, Aslin also argued that all sublooking time metrics (microstructure) are treated as error variance: 'Other potential metrics, such as sequences and duration of fixations that fall within the look-aways criterion, the number of look-aways, and the minimum and maximum look durations, are discarded' (p. 50). It thus seems reasonable to assume that this more finegrained analysis (e.g., looks toward agent, and looks toward the 'correct' location for incorrect reaches and vice versa) would provide a more detailed and definitive account of just what infants' looking times within these studies actually represent. This interpretation has resonance with early [e.g., Bates, Camaioni, \& Volterra, 1975] and later [e.g., Franco \& Butterworth, 1996] infancy research which demonstrated that infants' alternation of gaze direction between object and agent reflects a communicative act performed in order to intentionally share information and direct another person's attention to a desired outcome. This line of reasoning can also be seen in evidence within more advanced behavioural indices, such as protodeclarative point- 
ing [Camaioni et al., 2004; Liszkowski et al., 2004]. It thus seems reasonable to assume that a more comprehensive understanding of infants' performance on 'false belief' tasks may benefit from a similar line of reasoning.

In summary, we feel that a full grasp of the development of infant social understanding will only occur if we explore how this unfolds within changing patterns of social engagement [Moll, Carpenter, \& Tomasello, 2007]. Rather than simply assuming full competence or no competence, we need process models of the ways in which infants interact with others. Such information gives us a hint regarding what infants understand about such interactions. Such an interactional account, or what Reddy [2008] calls a second-person approach, will help us to avoid attempting to understand infants' skills in ways which either deny the need to identify clear developmental pathways, or assume that infant social learning can be acquired by simple rules bereft of interactions and relationships.

\section{References}

Aslin, R. (2007). What's in a look? Developmental Science, 10, 48-53.

Bates, E., Camaioni, L., \& Volterra, V. (1975). The acquisition of performatives prior to speech. MerrillPalmer Quarterly, 21, 205-224.

Behne, T., Carpenter, M., Call, J., \& Tomasello, M. (2005). Unwilling versus unable: Infants' understanding of intentional action. Developmental Psychology, 41, 328-337.

Camaioni, L., Perrucchini, P., Bellagamba, F., \& Collonnesi, C. (2004). The role of declarative pointing in developing a theory of mind. Infancy, 5, 291-308.

Carpenter, M., Nagell, K., \& Tomasello, K. (1998). Social cognition, joint attention, and communicative competence from 9 to 15 months of age. Monographs of the Society for Research in Child Development, 63, i-vi, 1-143.

Csibra, G., \& Southgate, V. (2005). Evidence for infants' understanding of false beliefs should not be dismissed. Trends in Cognitive Sciences, 10, 4-5.

Fischer, K.V., \& Bidell, T. (1991). Constraining nativist inferences about cognitive capacities. In S. Carey \& R. Gelman (Eds.), The epigenesist of mind: Essays on biology and cognition (pp. 199-235). Hillsdale: Erlbaum.

Franco, F., \& Butterworth, G. (1996). Pointing and social awareness: Declaring and requesting in the second year. Journal of Child Language, 23, 307-336.

Gergely, G., \& Csibra, G. (2003). Teleological reasoning in infancy: The naïve theory of rational action. Trends in Cognitive Sciences, 7, 287-292.

Haith, M.M. (1998). Who put the cog in infant cognition? Is the rich interpretation too costly? Infant Behavior and Development, 21, 167-179.

Leslie, A.M. (1987). Pretense and representation: The origins of 'theory of mind'. Psychological Review, 94, 412-426.

Leslie, A.M. (2005). Developmental parallels in understanding minds and bodies. Trends in Cognitive Sciences, 9, 459-462.

Liszkowski, U., Carpenter, M., Henning, A., Striano, T., \& Tomasello, M. (2004). Twelve-month-olds point to share attention and interest. Developmental Science, 7, 297-307.

Luo, Y., \& Baillargeon, R. (2007). Do 12.5-month-old infants consider what objects others can see when interpreting their actions? Cognition, 105, 489-512.

Moll, H., Carpenter, M., \& Tomasello, M. (2007). Fourteen-month-olds know what others experience only in joint engagement. Developmental Science, 10, 826-835.

Moll, H., \& Tomasello, M. (2004). 12- and 18-month-old infants follow gaze to spaces behind barriers. Developmental Science, 7, F1-F9.

Moll, H., \& Tomasello, M. (2007). How 14- and 18-month-olds know what others have experienced. Developmental Psychology, 43, 309-317.

O’Neill, D.K. (1996). Two-year-old children's sensitivity to a parent's knowledge state when making requests. Child Development, 67, 659-677.

Onishi, K., \& Baillargeon, R. (2005). Do 15-month-old infants understand false beliefs? Science, 308, 255-258.

Steering towards a Developmental Account of Infant Social Understanding
Human Development 2008;51:229-234 
Perner, J., \& Ruffman, T. (2005). Infants' insight into the mind: How deep? Science, 308, 214-216.

Poulin-Dubois, D., Sodian, B., Metz, U., Tilden, J., \& Schoeppner, B. (2007). Out of sight is not out of mind: Developmental changes in infants' understanding of visual perception during the second year. Journal of Cognition and Development, 8, 401-425.

Reddy, V. (2008). How infants know minds. Cambridge: Harvard University Press.

Ruffman, T., \& Perner, R. (2005). Do infants really understand false belief? Trends in Cognitive Sciences, 9, $462-463$.

- Sirois, S., \& Jackson, I. (2007). Social cognition in infancy: A critical review of research on higher order abilities. European Journal of Developmental Psychology, 4, 46-64.

Sodian, B., \& Thoermer, C. (2008). Precursors to a theory of mind in infancy: Perspectives for research on autism. The Quarterly Journal of Experimental Psychology, 61, 27-39.

Sodian, B., Thoermer, C., \& Metz, U. (2007). Now I see it but you don't: 14-month-olds can represent another person's visual perspective. Developmental Science, 10, 199-204.

Southgate, V., Senju, A., \& Csibra, G. (2007). Action anticipation through attribution of false belief by 2-year-olds. Psychological Science, 18, 587-592.

Surian, L., Caldi, S., \& Sperber, D. (2007). Attribution of beliefs by 13-month-old infants. Psychological Science, $18,580-586$.

Tomasello, M., \& Haberl, K. (2003). Understanding attention: 12- and 18-month-olds know what is new for other persons. Developmental Psychology, 39, 906-912.

Wan, H., Aggleton, M.W., \& Brown, J. (1999). Different contributions of the hippocampus and perirhinal cortex to recognition memory. Neuroscience, 19, 1142-1148.

Wimmer, H., \& Perner, J. (1983). Beliefs about beliefs: Representation and constraining function of wrong beliefs in young children's understanding of deception. Cognition, 13, 103-128.

Woodward, A.L. (1998). Infants selectively encode the goal object of an actor's reach. Cognition, 69, 134.

Woodward, A.L. (1999). Infants' ability to distinguish between purposeful and nonpurposeful behaviour. Infant Behavior and Development, 22, 145-160.

\section{Editor's Corner and Letters to the Editor}

The Editors invite subscribers and readers of the journal to send in letters to the editor in response to essays in the Editor's Corner, articles, commentaries, and essay reviews that appear in Human Development. The letters will be reviewed by the Editors, and those that are selected will be posted on the journal web page www.karger.com/journals/hde/hde_jh.htm, and sent by e-mail as a pdf file to subscribers. The letters will be sent out every other week to maintain a dialogue in-between journal issues. If you wish to submit a letter to the editor, send it by e-mail to HDletter@uic.edu.

Readers who wish to suggest topics for the Editor's Corner may do so by sending an e-mail to the Editor at Humandev@berkeley.edu. 